\title{
RENK-ANLAM-MEKAN İLIŞKISİ
}

\author{
Banu MANAV \\ İstanbul Kültür Üniversitesi, İç Mimarlık ve Çevre Tasarımı Bölümü, Türkiye \\ b.manav@iku.edu.tr
}

\begin{abstract}
ÖZ
İç mimari tasarımda, hacim ölçeğindeki önemli tasarım parametrelerinden bir tanesi olan "renk" konusu, mekana kimlik kazandırmak, mekan psikoloji ve kişisel izlenimler açısından, üzerinde dikkatle çalışılması gereken bir konudur. Renk kullanımı iyi planlanmazsa istenilen renk duyulanmasından farklı bir sonuç ile karşılaşılabilir. Bu nedenle renk kullanımı için mekan türüne bağlı olarak bir renk düzeni kurulmalı ve mekan algılamayla olan ilişkisi planlanmalıdır. Bu çalışma, renk konusunun mekanın iletişim gücüne katkısı renk,-anlam-mekan ilişkisi ve mekan algısında renk etkisi üzerinden tartışılacaktır. Renk kompozisyonu kavramının tanıtılması, mekan tasarlamak için renk kompozisyonu yaratmanın önemi de ele alınacaktır.
\end{abstract}

Anahtar kelimeler: renk, mekan, görsel alg1, renk kompozisyonu

\section{COLOR-THEME-SPACE INTERACTION}

\begin{abstract}
In interior design, at the volume scale, colour is an important design paramater. During the design process, colour is a crucial subject for space identity, space psychology and personal impressions. In case colouring process is not planned well, the final product is an unexpected situation. For this reason, colour order shall be according to the space typology and its relation to space perception shall be planned. The present paper focuses on design parameters which are effective on colour perception, colour and space psychology and the importance of colour compositions.
\end{abstract}

Keywords: color, space, visual perception, color composition

\section{Giriş}

Mekanın anlamsal çözümlemesine neden olan deneyimlemede, beş duyu organıyla gerçekleşen ve belleğin katkısıyla anlamsal bütünlüğe varan süreç algı mekanizmasında etkilidir. Bu süreç, mekan çözümlemede algı mekanizmasının bütüncül bir sistem içerisinde paralel duyumlama süreçlerinin birleşimiyle gerçekleştiğini açıklamaktadır. Yapma çevreler, kimi zaman kişinin beklentilerine oldukça uzak kalmakta ve algı düzeyi düşük, memnuniyet açısından olumsuz sonuçlar doğurmaktadır. $\mathrm{Bu}$ durumun tersine, kendine özgün kimliğiyle dikkati çeken yapma çevreler de kişiler için "özel, seçkin, güzel ve benzeri" tanımlarla anılmaktadır. Bu yazı kapsamında renk konusunun mekanın iletişim gücüne katkısı renk,-anlam-mekan ilişkisi ve mekan algısında renk etkisi üzerinden tartışlacaktır. Renk kompozisyonu kavramının tanıtılması, mekan tasarlamak için renk kompozisyonu yaratmanın önemi de ele alınacaktır.

\section{Renk, Anlam ve Mekan}

Herhangi bir biçim, doku veya renk belleğimizde bir anlam oluşturabilir. Mutluluğun Mimarisi adlı eserinde Alain de Botton, iç dünyamız ile görsel-duyusal algımız için dilimizde birçok metafor olduğunu ifade etmektedir. Botton'un örneklemleri arasında, güçlü kavramını anlatmak için yüksek bir yapı, ağır ve kalın bir biçim kullanmak fikri olduğu, dinginlik için az katlı, yatayda sürekliliği olan bir 
biçim kullanmak önerisi, yumuşak izlenimi için özgül ağırlığı hafif ve açık renk bir malzeme, şeffaf için saydam/yarı saydam malzemeler, hatta demokrasinin simgesi için saydam malzemelerin seçilebileceği anlatılmaktadır (Botton, 2010:80, 98-105). Tüm bu anlamsal ilişki kurma çabaları, mekanı deneyimlemede etkili olmaktadır. Kişilerin çevresindeki elemanlara benzettiği yapı/ mekan /nesne ile iletişim kurması daha kolay ve başarılı olmaktadır. İletişim kurma sürecinde psiko-sosyal açıdan renk kavramının katkısı, fiziksel ve psikolojik açıdan kişileri etkilemesi nedeniyle önemlidir.

Literatürde, rengin anlamsal etkisini araştıran çalışmalar ve bu konuda bazı belirlemeler yer almaktadır. Mahnke tarafından başlatılan, üzerinde birçok araştırmacının çalıştığı renk araştırmaları sonucunda renklerin kişilerde olumlu ve olumsuz etkiler uyandırdığı sonucuna varılmıştır (Mahnke, Meerwein, Rodeck-2007:30-31). Kırmızı gücü, neşeyi, mutluluğu harekete geçirir, kullanıldığ mekanda dinamik, canlı bir etki yaratır. Negatif yüzüyle kırmızı korkuyu, aşırı öfkeyi, kontrolsüz tutkuyu açığa çıkartır, kan basıncını arttırır. Turuncu enerji verir, yaratııllı̆̆ ve hırsı harekete geçirir, sicak bir atmosfer yaratılmasında etkilidir. Ancak turuncu rengin baskın kullanımı nevroz ve huzursuzluk nedenidir. Neşe veren bir renk olan sarı bilgeliği, sezgisel kavrayışı ortaya çıkartır, kullanıldığ 1 ortamda dikkat çekici bir etki yaratır. Altın sarısı kullanıldığg mekanda zenginliği ve şöhreti temsil eder. Negatif yüzüyle sarı, çok parlak ve dikkat çekici olduğundan sinir sistemini fazla uyarır, rahatsızlık verebilir. Doğanın rengi olan yeşil bedensel ve zihinsel açıdan yorgunluğu gideren huzurlu ve dingin bir ortam yaratmak için kullanılan bir renktir. Ancak, yeşil baskın olarak kullanıldığında sakinlik temsili tembelliği çağrıştırabilir, koyu yeşil sıkıcı, tedirgin edici bir ortam yaratabilir. Mavi sakinliğin, umudun, uyumun rengi olarak bilinir, bu özelliğiyle sessiz ve sakin bir ortam yaratmak istenildiği ortamlarda tercih edilir. Negatif açıdan mavi, hüzün ve iç karartıcı bir etki yaratabilir, mekan donuk, statik, sıkıcı hissedilebilir. Mor ile mavi arasında bulunan lacivert mantık, sezgi ve disiplini yaratıcılıkla birleştirirken, negatif açıdan bakıldığında durgunluk, zihinsel yorgunluk getiren bir renktir (Fraser, Banks, 2004:20, Sharma,2007:23-29). Beyaz ve siyah türsüz (akromatik) olarak bilinmektedir. Beyaz saflığın ve temizliğin temsilidir, beyaz 1şık gücün sembolüdür, ancak beyaz 1şık altında her şey kendi öz renginde görünür, mekana ait tüm kusurlar görünür. Siyah, 1şığın yokluğunu temsil eder, yaşamın sonunu ifade eder, mekandaki sınırların görünürlüğünü azaltır, kimi zaman yok eder.

Bilimsel renk dizgelerinde bu değişkenler tür/değer/ doymuşluk bileşenleridir. Kiremit kırmızısı, ateş kırmızısı, Ferrari kırmızısı temelde "kırmız”" renk türünü ifade etmekle birlikte, değer ve doymuşluk bileşenleri bakımından ayrılık göstermektedir. Renk çalışmalarında, belirli bir renkle ilgili en doğru tanımlamayı yapabilmek için o renge ait değişkenleri bilmek önemlidir.

Renk, günlük yaşantımız içerisinde bir anlatım dili oluşturmuştur. Bu anlatım dili, belirli renklerle ilgili bir kodlama da oluşturmaktadır. Kişilerin belleğindeki kodlama, mekan bileşenlerinin kişisel duyumları uyarmasına bağlı olarak negatif algı ile pozitif algı arasında değişebilir. Negatif algı, bir mekan için görsel duyum eşiği minimum olduğunda, mekansal uyartılardan gelen sinyaller zayıfladığında ortaya çıkmaktadır. Donatılar, yüzey renkleri türsüz ise, diğer bir deyişle, siyah-beyaz ekseninde, akromatik renk düzeni oluşturulmuşsa negatif algı ortaya çıkmaktadır. Tek bir renk türü, yalnızca değer bileşeninde değişikliğe uğramışsa, yine negatif alg1 oluşur; mekan monoton, sıkıcı, durağan gibi olumsuz sıfatlarla tanımlanır. Pozitif algı ise, bir mekandaki renk kompozisyonu farklı renk türleri ile oluşturulmuşsa, aynı renk türüne ait yüksek doymuşluk derecelerinde renk örnekleri birlikte kullanılmışsa ve/veya yüzey dokuları baskın ise ortaya çıkmaktadır (Manav, 2011:93-102). Belirli bir renk kompozisyonu yaratılmayan bir durumda birden fazla renk türü, değer ve doymuşluk bileșenleri belirli adımlarla bir düzen olușturmayacak biçimde kullanıldığında Şekil 1'de görüldüğü gibi istenmeyen bir durum oluşur. Bu koşulların kişiler üzerindeki etkisi istatistiksel olarak da ölçülebilmektedir. Küller, Mikellides ve Janssens, günışığı almayan bir hacimde renk algılama ve kişilerin performansına renk etkisi araştırmaları yapmışlardır. Deneysel çalışmalarında renk algısını, karşıt sıfat çiftleri üzerinden anlamsal farklılıklar skalası ile ölçmüşlerdir. Çalışmaları, rengin kişiler üstündeki etkisinin araştırma yöntemleri ile ölçülebileceğini göstermesi açısından önemlidir. 


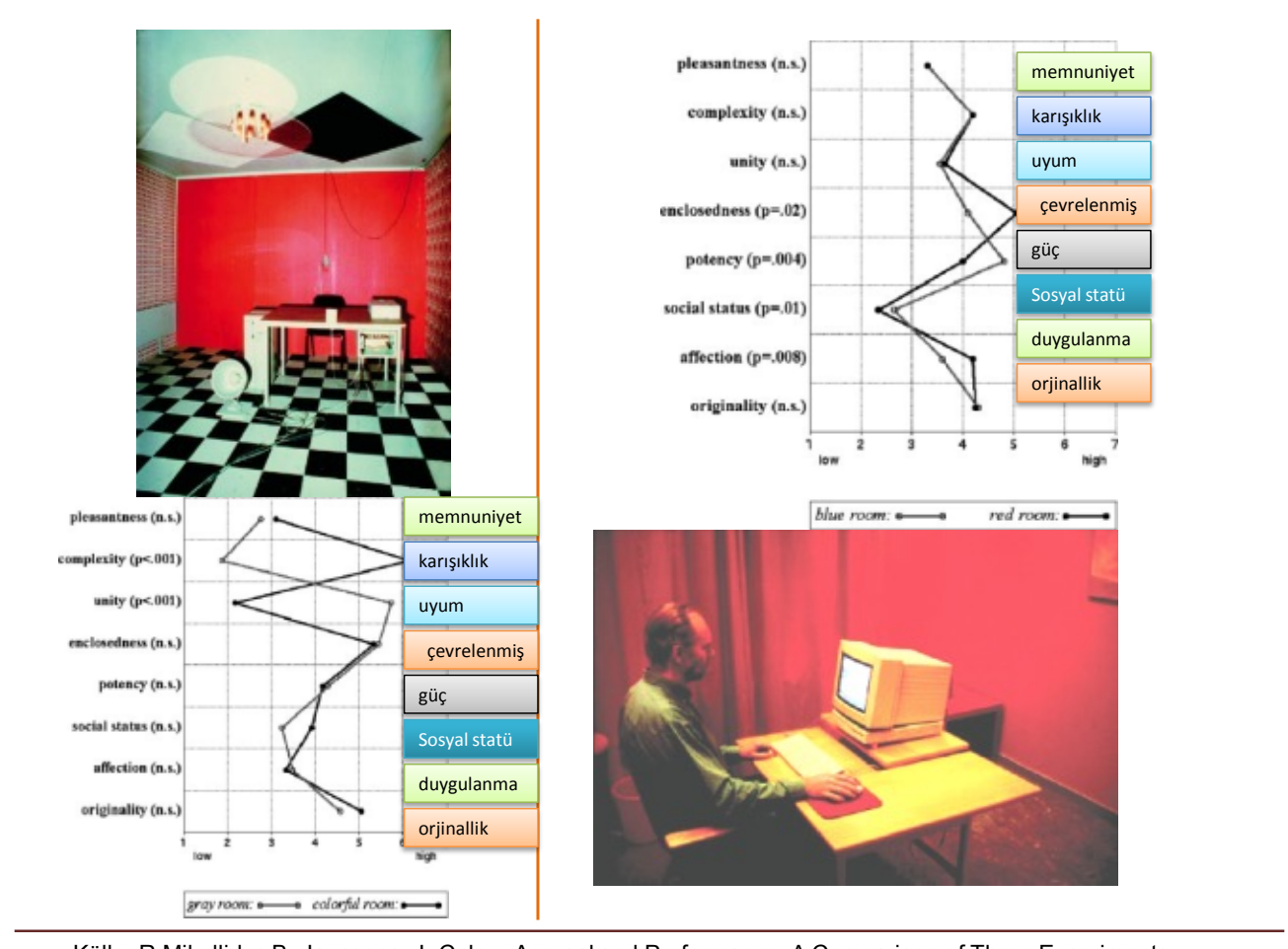

Küller R,Mikellides B, Janssens J, Colour,Arousal and Performance; A Comparison of Three Experiments, Color Research and Application, Vol 34, No:2, pp:141-152, 2008.

Şekil 1. Renk ve mekan izlenimlerinin akromatik ve monokromatik test odalarında değerlendirilmesi

\section{Renk Kompozisyonları ve Mekan Tasarımı}

Rengi tanımlamak için çeşitli dizgeler kullanılmaktadır. Geçmişte bilimsel olmayan yaklaşımlarla benzetme (analojik) yöntemlerle renkler adlandırılırken, günümüzde bilimsel dizgeler yardımıyla rengi üç boyutlu olarak anlatabilmekteyiz. Bu amaca uygun olarak Munsell Renk Dizgesi, RAL, CIE gibi çeşitli renk sıralama dizgeleri geliştirilmiş ve tanımlanmıştır. Bu sistemlerin amacı, rengi boyalı yüzeylerden yararlanarak ifade edebilmek, benzer renkleri belirli bir düzen içerisinde yan yana getirebilmektedir. Böylece, renk herkes tarafından anlaşılabilen ortak bir dilde tanımlanabilmektedir.

Renk sistemleri, oluşturulması önerilen renk düzenlerini, fonksiyonu tanımlanmış bir mekan için renk kompozisyonu oluşturabilmek amacıyla kullanılmaktadır. Renk düzeni oluştururken, rengin bileşenleri arasındaki karşıtlıklar değiştirilerek birbirine benzemeyen çok sayıda renksel görünümler yaratılabilir.

Bir görme alanı içinde yan yana gelen yüzeylerin anlam ve etkisi ise yüzey renklerinin tür, değer ve doymuşluk bileşenleri arasındaki ayrımların (karşıtlıkların) büyüklüklerine göre değişmektedir (Yavuz,Ünver,2010: 411-418). Şekil 2, sarı bir zemin üzerinde mavi donatıların görsel algıya etkisini göstermektedir. Arka fon/yüzey-detay/nesne algısında, birlikte kullanılan renklerin bileşenleri ve dalgaboyları önemlidir. Kısa dalgaboylu renkler, uzundalgaboylu renklere göre daha parlak ve yakın gibi algılanmaktadır. Şekil 2 de, "a" ile belirtilen örneklemde mavi renkteki detay sarı renkteki fon üzerinde, daha yüksek veya daha ön planda gibi algılanmaktadır. Aynı şekilde, "b" ile belirtilen örneklemde sarı renkteki detay mavi renkteki zeminden daha alçak veya daha geri planda gibi algilanmaktadır. 

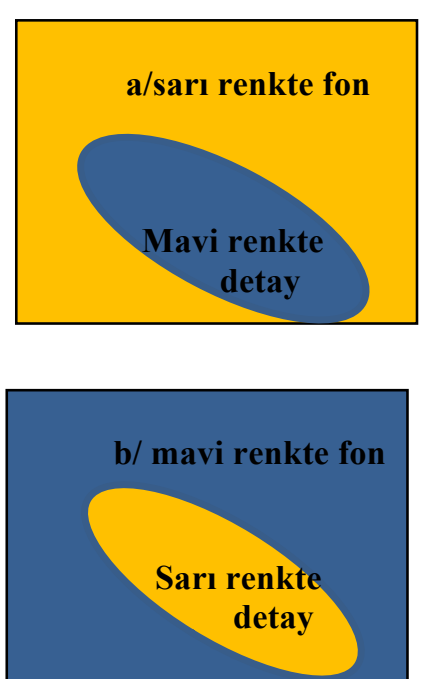

Şekil 2. Arka fon/yüzey - detay/nesne ilişkisi Kaynak: Manav,Form-Doku-Renk Ders Notları,2013

Renklerin birlikteliğinde bir mekan sıcak-soğuk-samimi-rahat ve benzeri sıfatlarla tanımlanır ve bir kimlik kazanır. Monokrom (tek renkli) renk ve tavan-duvar-döşeme yüzeyleri arasında tür-değerdoymuşluk açısından fark olmaması durumunda, mekan monoton ve tekdüze algılanacaktır.

Mekan kurgusunda düşey ve yatay düzlemlerde hangi renk düzenlemesi ile renklerin psikolojik ifadesinin güçleneceği soyut renk kompozisyonları üzerinden çalışılabilir. Görsel algılamanın önemi de dikkate alınarak, odak noktalarının hiyerarşisi düşünülerek renk türü (değer ve doymuşluk faktörleriyle birlikte) seçilebilir. Seçilen aydınlatma elemanının renk özellikleri de seçilen renk türleriyle birlikte ele alındığında daha başarılı çözüm önerileri sunulacaktır (Fraser,2004:32-36). Aşağıdaki şekilde, iç mekanda kullanılan malzemelere ait renk bileşenlerinin değiştiği durum için algılamadaki fark gösterilmektedir. Renkler, aralarındaki karşıtlık farkına bağlı olarak algılanmaktadır. Karşıtlık farkı azaldıkça görsel algı zayıflamaktadır. Renklerin, kendi "öz renginden” uzaklaşması, olduğundan farklı bir renk türünde veya daha koyu, açık renkte gözlemlenmesi görsel algıyı zayıflatmaktadır. Renk bir binanın karakterini ve yansıtması istenen duyguları ifade etmekte bir araç olarak kullanılabilir; çocuklar için tasarlanacak bir bina "neşeli, canlı" bir görünüşe sahip olmalı, prestij göstergesi bir bina için "sade, şık, etkili” bir tasarım yapılmalıdır.

Tek bir renk türü ve/veya renk bileşeni iç mekanda bir renk düzeni oluşturmak ve renk kompozisyonu tamamlamak için yeterli olmayacaktır. Bunun nedeni, mekan organizasyonunda işlev açısından birbirinden farklı birçok alan bulunmasıdır. Bu amaçla renk kompozisyonu ve şemasına ihtiyaç duyulmaktadır. Kullanılan renk kompozisyonlarında, en etkin bileşen, iç yüzeylerin yansıtma çarpanıyla ilgili olması ve yüzeyin açıklık-koyuluk derecelendirilmesi ile ilgili olan "değer" bileşenidir. İkinci etkin bileşen, rengin kendi öz rengine yakınlığını, canlı/parlak olmasını etkileyen "doymuşluk" bileşenidir. Üçüncü sırada etkin olan bileşen rengin adını belirleyen "tür" olarak ifade edilebilir.

Rengi malzeme ve 1şıktan bağımsız olarak düşünmek mekan algılama bakımından eksik sonuçlar doğurur. Rengi, malzemenin özelliklerinden bir tanesi olarak, aydınlatan 1şığın özelliklerine bağlı olarak anlamlandırırız. Aynı renge boyanmış iki tekstil malzemenin kullanımını düşünürsek; örneğin parlak bir saten kumaş ve bir kadifenin anlatım dili farklıdır. Saten parlak ve hafif, kadife derin ve sicak bir etki yaratacaktır (Rasmussen,1994:179-182).

Mekan içinde malzemelerin birlikteliği düşünüldüğünde, seçilen malzemelerin renk özellikleri, kapladıkları yüzey alanı ile birlikte düşünülmelidir. Tavan-duvar-döşemelerde kullanılan malzemeler geniş yüzey alanına sahip olduğu için, seçilen malzemenin renk özellikleri, değer (içindeki gri miktarı; 
açıklı̆̆ı-koyuluğu) ve doymuşluk (kendi öz rengine yakınlığı; soluk-parlak) öğeleri de dikkate alınarak seçilmelidir. Şekil 3 rengin bu etkisine bir örnektir. Kişilerin mekan izlenimlerinde renk - malzeme doku - 1şık etkileşimi etkin rol oynamaktadır.

Rengin psikolojik etkileri unutulmamalı, malzemenin öz (kendi) rengine yakınlığının algılamaya etkisi düşünülmelidir. Malzemenin yüzey özellikleri (pürüzlü, parlak gibi), kalınlığı, rengi, geçirgenliği (saydam, yarı saydam veya saydamsız olması durumu), üzerlerine düşen ışığın renk özellikleri ile bir etkileşim içine gireceğinden, yansışmalara bağlı olarak malzemelerin tür, değer ve doymuşlukla ilgili özellikleri etkilenecektir (Manav, 2007:32-34).
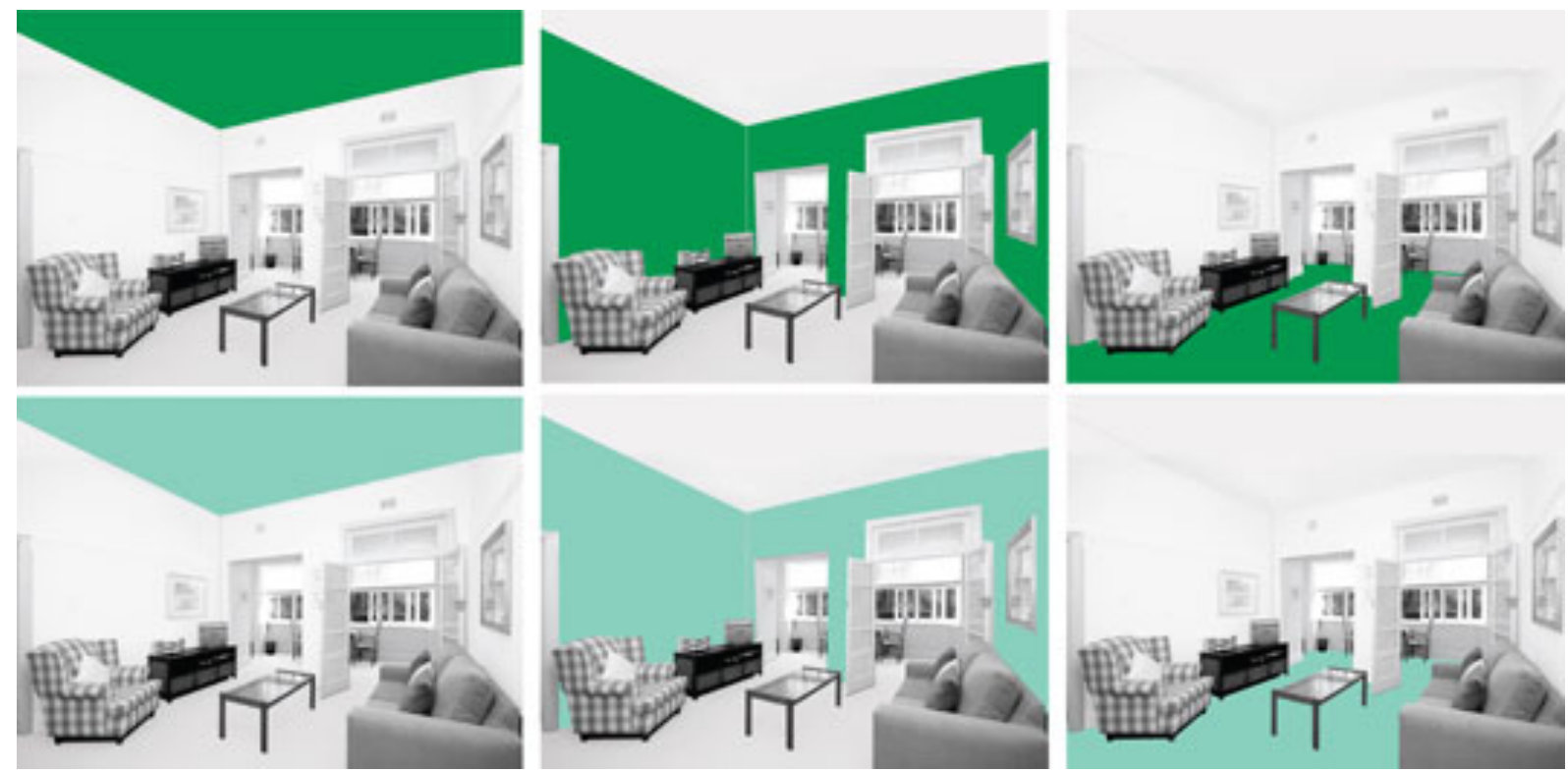

Şekil 3. Rengin farklı yüzeylerde kullanılması ve mekan algısına etkisi

Rengin psikolojik etkisine bağlı olarak, mekanın duvar renkleri değiştikçe kişilerde oluşan etkileşim de değişecektir. Aynı mekan mavi renk kullanıldığında daha dingin, sakin olarak algılanırken, sarı renk kullanıldığında daha canlı, dinamik algılanabilir.

\section{SONUÇ}

Görsel algıyı, malzemenin fiziksel özellikleri ile birlikte (doğal, suni,parlak,mat, pürüzlü yüzey ve benzeri) renk özellikleri de etkilemektedir. Rengin kişilerde uyandırdığı izlenimler mekan algısındaki değerlendirme kriterlerini etkilemektedir. Renk kompozisyonlarına ilişkin kararlar, malzeme-dokuaydınlatma tasarımı ile birlikte projelendirme sürecinde alınan tasarım kararları olmalıdır. Bunun en önemli nedeni, iç mimari tasarıma ait tüm planlamaların bütünleşik bir şekilde tamamlanmasının gereğidir. Mekan kimliği, tasarlanan söz konusu mekanın, aynı işleve hizmet veren diğer örneklerden farklı olmasını sağlayacaktır. Bu farkın oluşmasında mekanda oluşturulan renk etkisi ve anlam iletisi önemlidir. Tasarlanan yapma çevrede renklerin birlikteliğinde mekan algılama gerçekleştiği için oluşturulan renk düzenlerine dikkat edilmelidir. Rengin tür-değer-doymuşluk bileşenlerindeki değişimin rengin psiko-sosyal etkisi bakımından da düşünülmesi gerekmektedir.

\section{KAYNAKÇA}

1.A.Botton, Mutluluğun Mimarisi, 4. Basım, Sel Yayıncılık, 2010.

2.T.Fraser, A.Banks The Complete Guide to Colour, Cambridge: The Ilex Press, 2004.

3.B.Manav Hacimde Bir Tasarım Parametresi Olarak Renk, Gazi Üniversitesi Güzel Sanatlar Fakültesi, Sanat ve Tasarım Dergisi, 8, 93-102 (2011).

4.B.Manav Fiziksel Çevre Bileşenlerinden Işık ve Renk İlişkisi Mimarlıkta Malzeme:Mimarlık ve Yapı Malzemeleri Dergisi, sayı:6, 32-34, 2007. 
The Turkish Online Journal of Design, Art and Communication - TOJDAC July 2015 Volume 5 Issue 3

5. B.Manav Form-Doku-Renk Ders Notları, 2013.

6. S.E.Rasmussen Yaşanan Mimari, İstanbul:Remzi Kitabevi, 1994.

7. R.Sharma Renklerle Terapi, İstanbul:Nokta Kitap, 2007.

8. Yavuz M, Ünver R. Yap1 Yüzü Renk Düzeni ve Işık Rengi İlişkisi Üzerine Bir İnceleme,

Yapı Fiziği ve Sürdürülebilir Tasarım Kongresi, 4-5 Mart 2010, YTÜ Oditoryumu, Yıldız Yerleşkesi, ss:411-418. 